\title{
Correction: Aberrant JmjC domain-containing protein 8 (JMJD8) expression promotes activation of AKT and tumor epithelial-mesenchymal transition
}

\section{Yao Su (D) X Xueying Wang $\cdot$ Zhen Guo (D) Jun Wang (D)}

Published online: 26 March 2021

(c) The Author(s), under exclusive licence to Springer Nature Limited 2021

\section{Correction to: Oncogene}

https://doi.org/10.1038/s41388-020-01446-1

After publication of this article, the authors noticed that several representative images included in Figs. 1B, C, 3E,
4A, C, 6A, 7E, G and 8D were inadvertently misused. These errors have been corrected using original images and the revised Figures containing corrected images are included below.

The original article was corrected. 

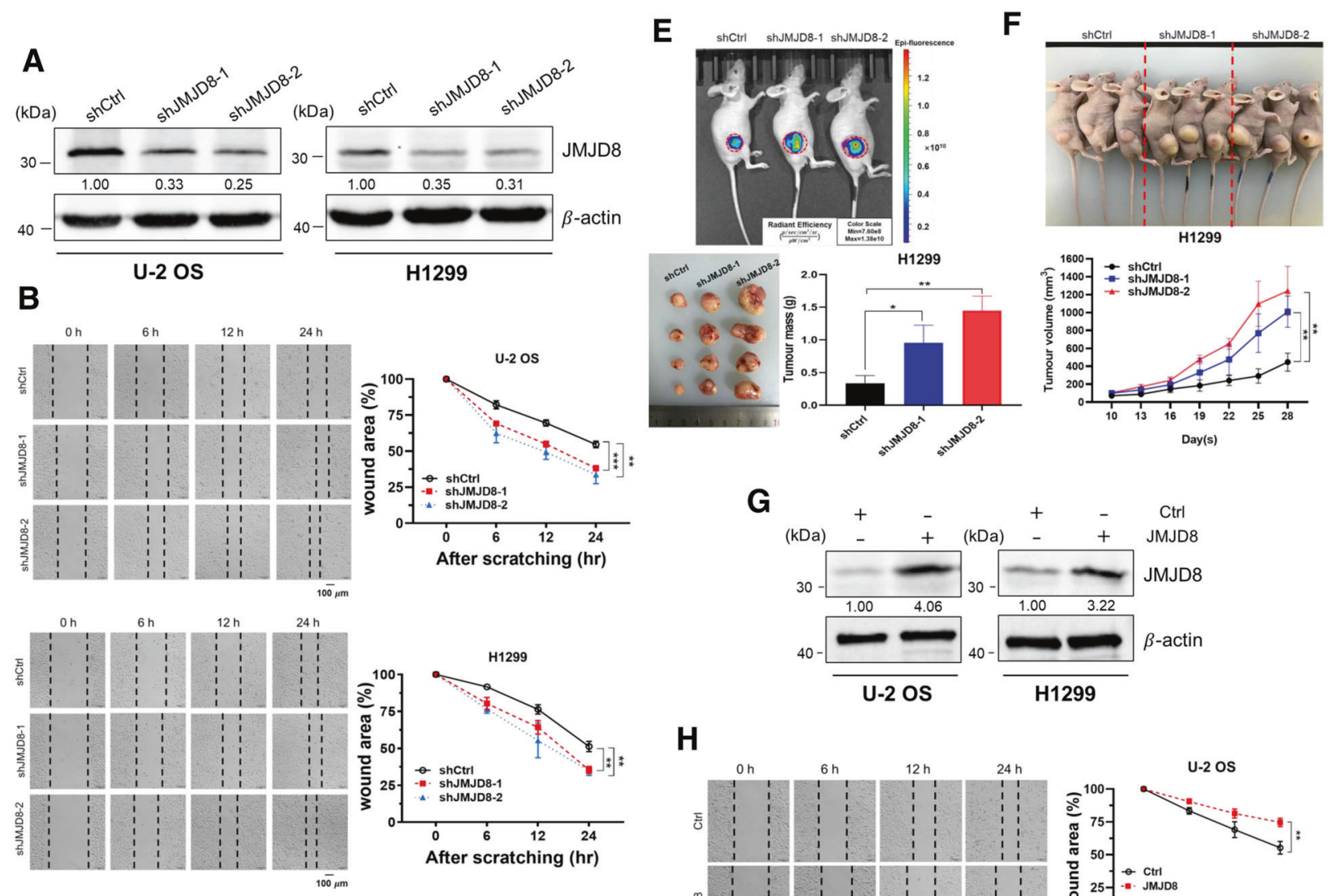

C
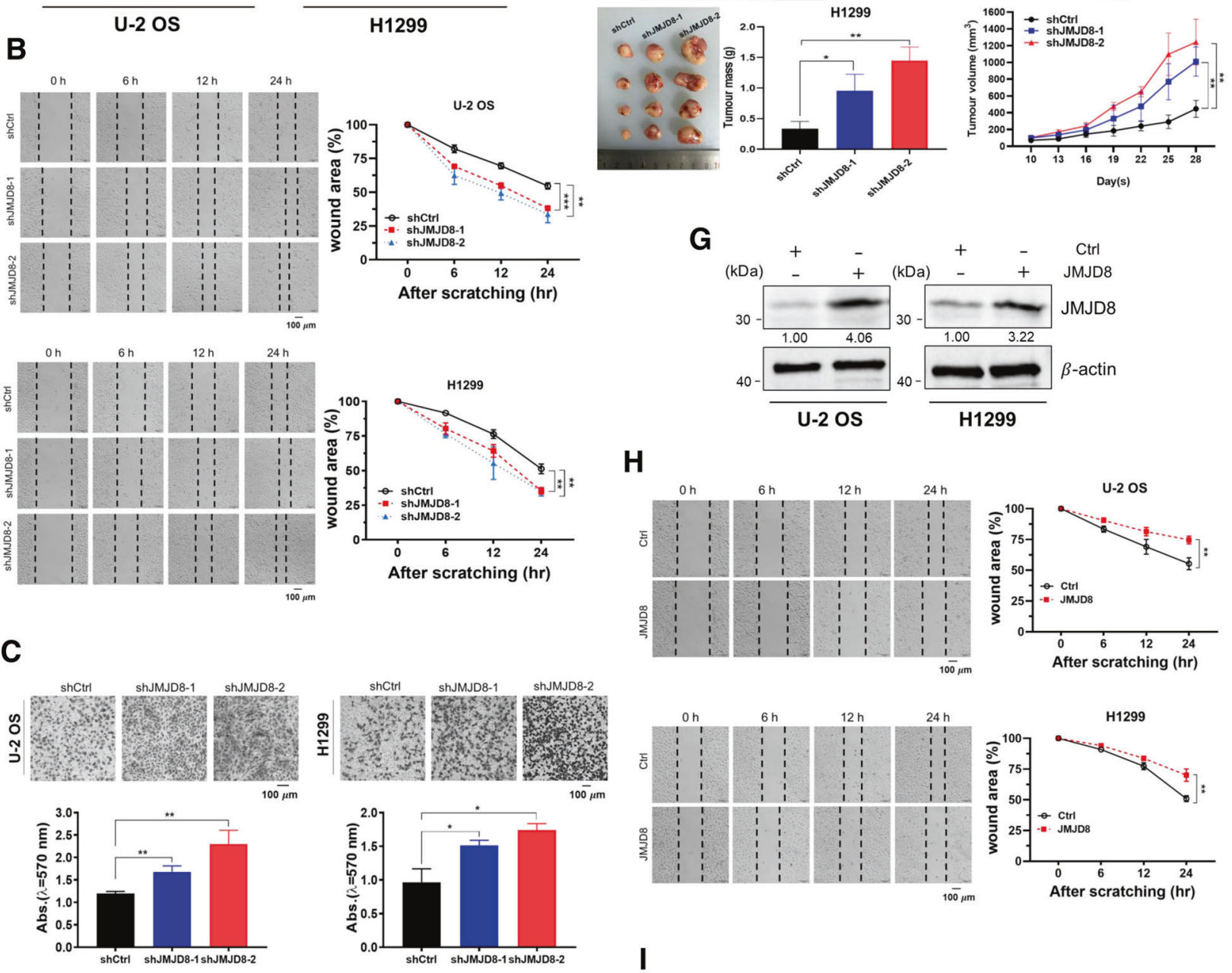

D
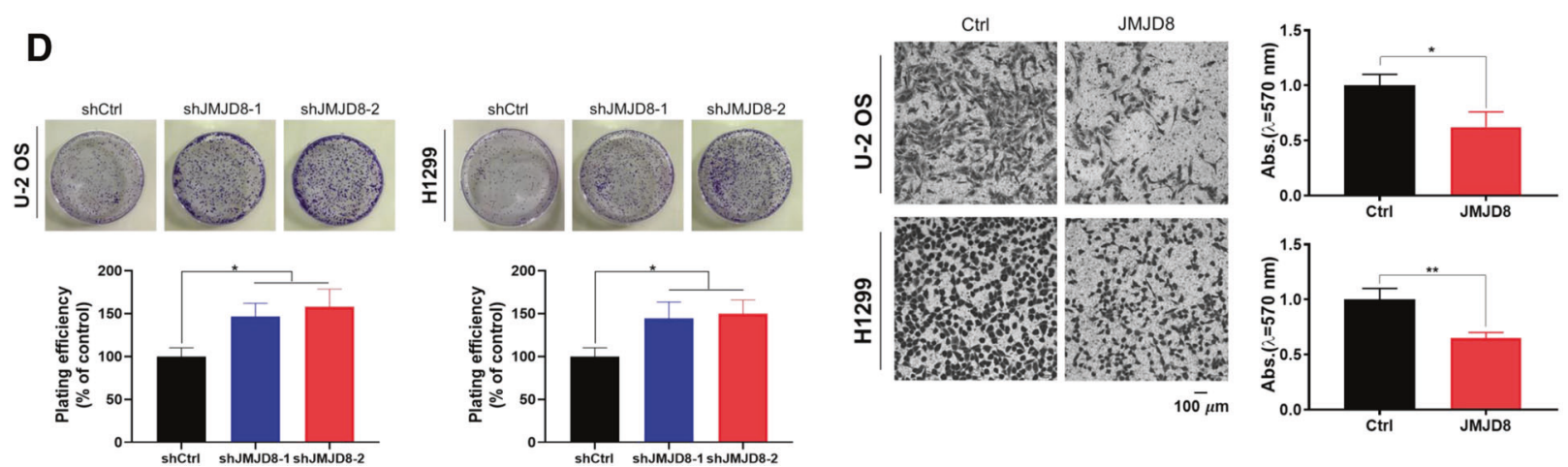

Fig. 1 


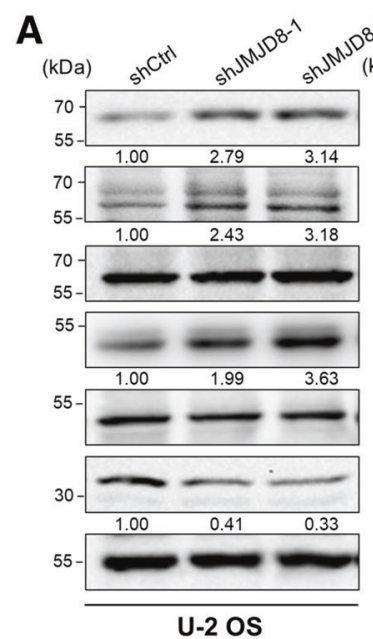

C
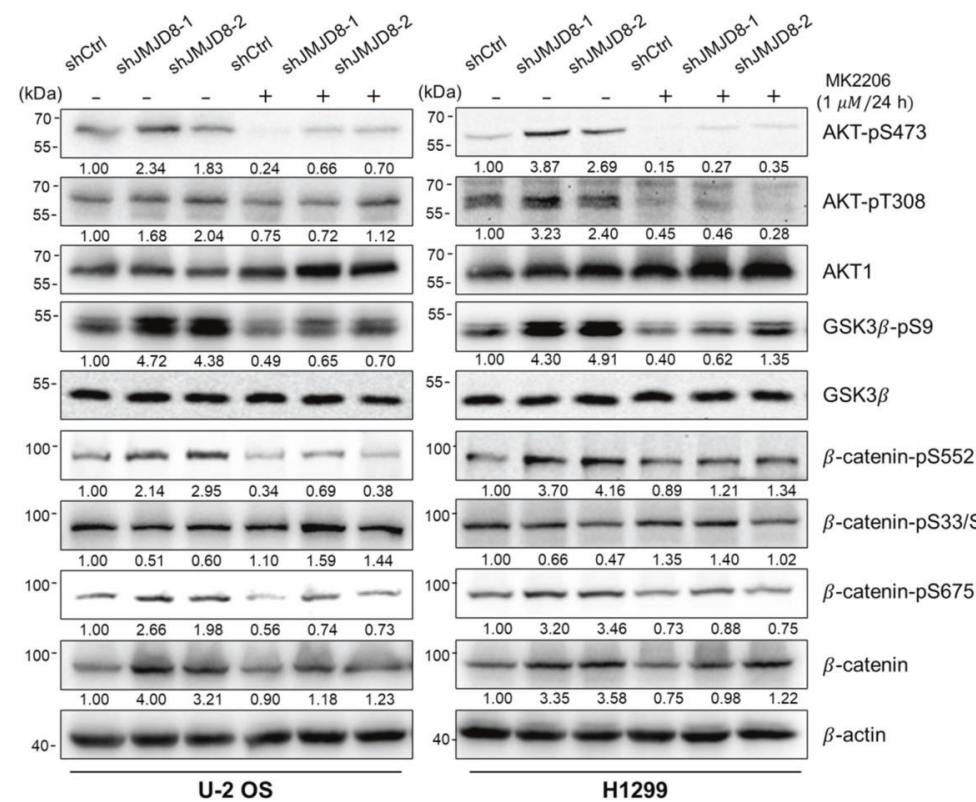

D

$\mathrm{U}-2$ os

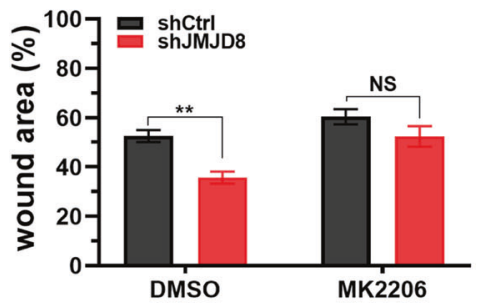

H1299

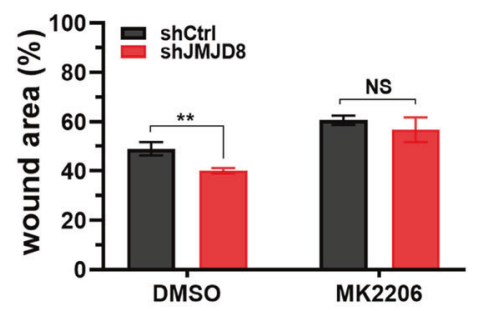

E
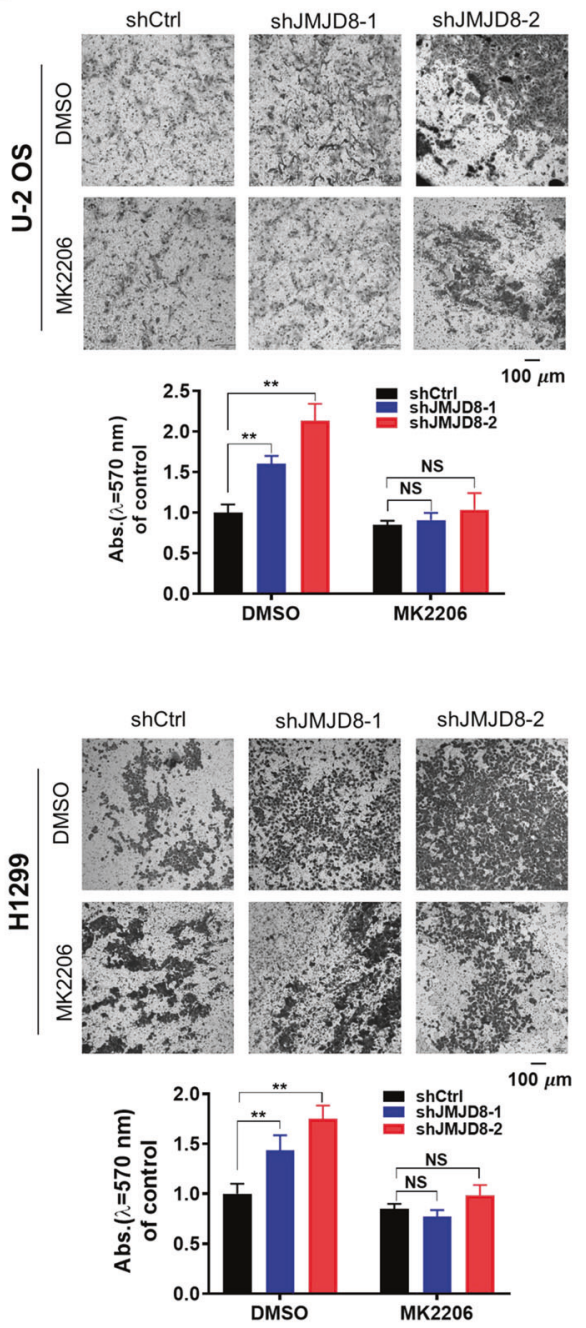

Fig. 3 
A

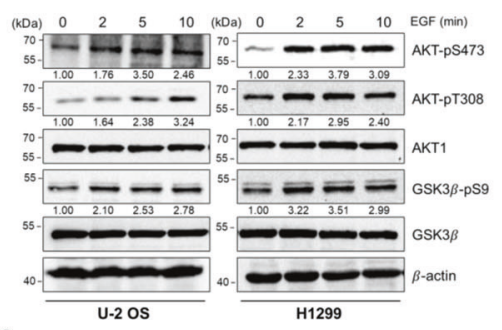

C

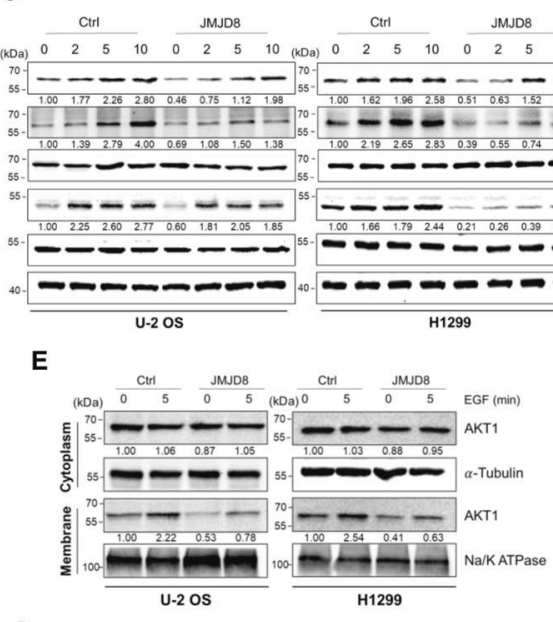

G

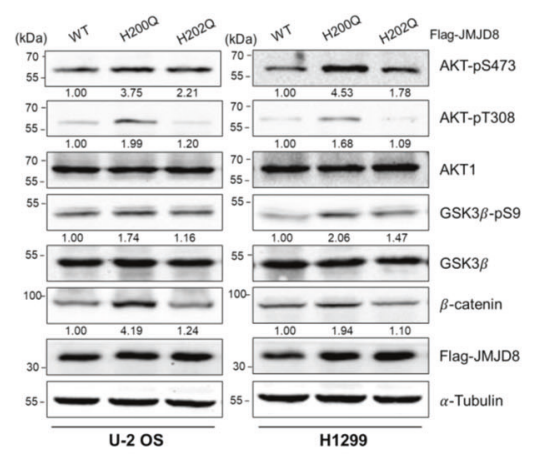

$\mathbf{J}$
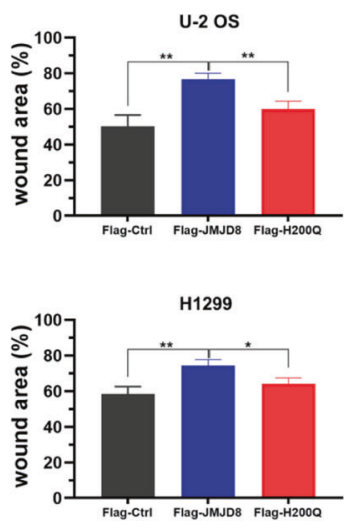

B

K

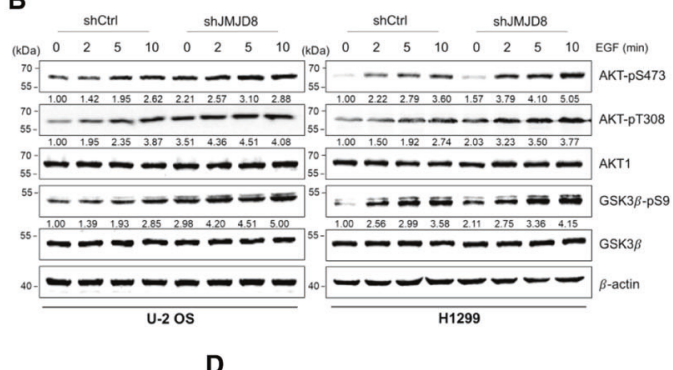

D

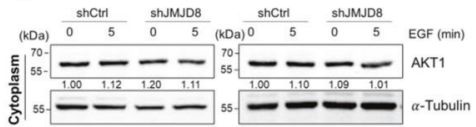

AKT1

Na/KATPase

U.2OS

$\mathbf{F}$ JMJD8

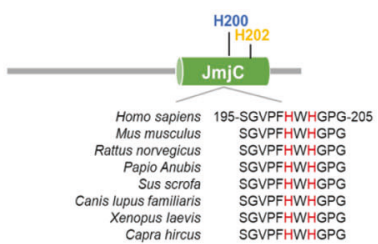

H

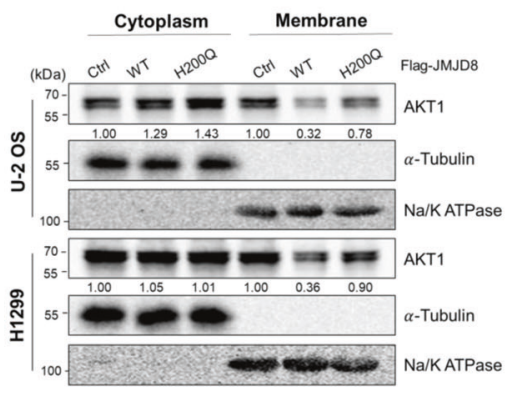

I
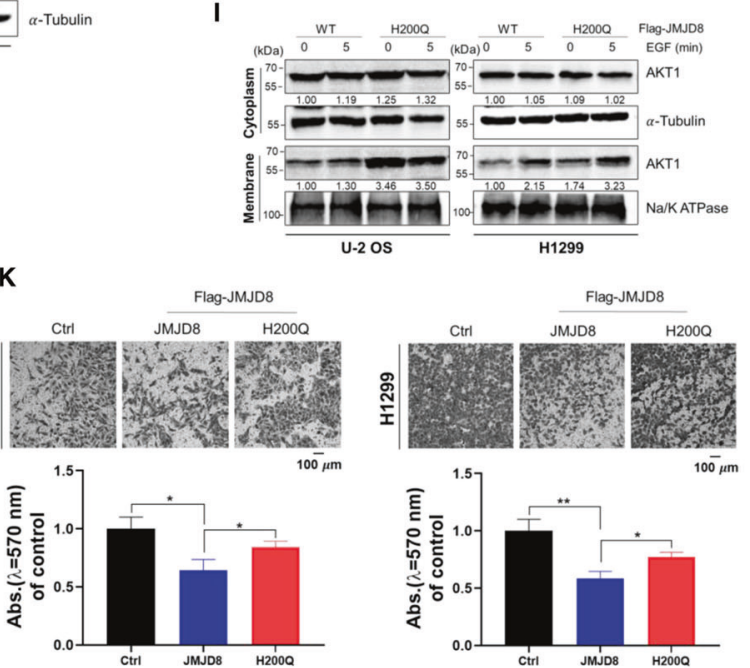

Fig. 4 
A

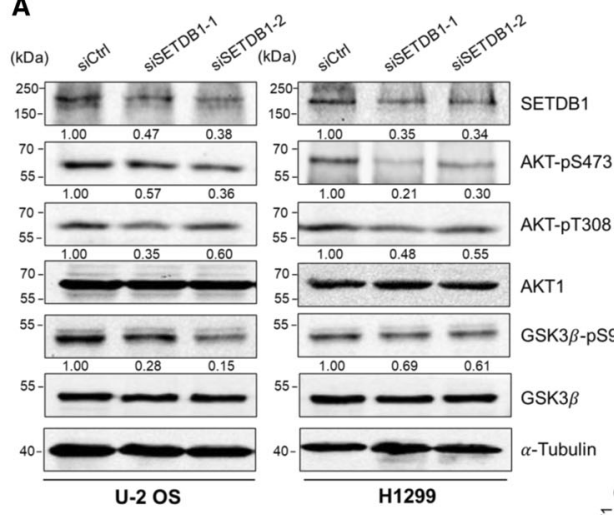

C

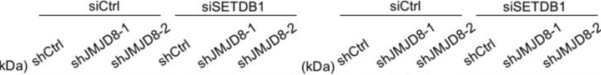

(KDa)

\begin{tabular}{llllll}
70.00 & 1.74 & 1.50 & 0.63 & 0.77 & 0.85 \\
\hline
\end{tabular}

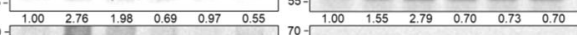

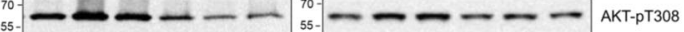

$\begin{array}{lllllllllllllll}1.00 & 227 & 1.69 & 0.60 & 0.23 & 0.35 & 1.00 & 2.50 & 2.14 & 0.94 & 1.25 & 0.79\end{array}$

70-

-

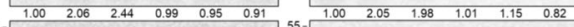

- - - -

${ }^{40} \longrightarrow{ }^{40} \longrightarrow$ -

U-2 OS H1299

$\mathbf{F}$

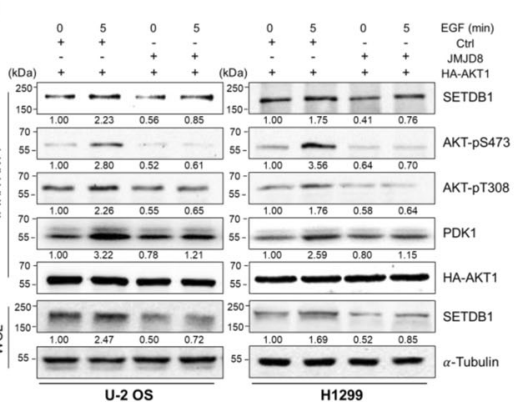

$\begin{array}{lllllllllll}\text { H } & 0 & 5 & 0 & 5 & 0 & 5 & 0 & 5 & \text { EGF (min) }\end{array}$

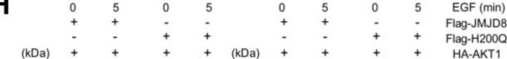

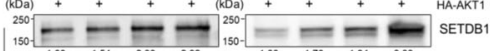

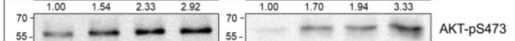

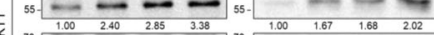

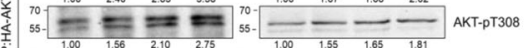

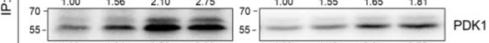

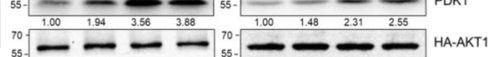

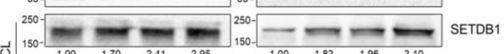

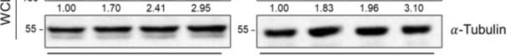

U.2 OS

J SICHI SSETDB1

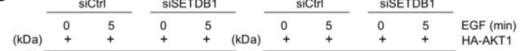

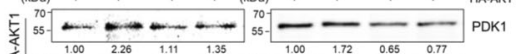

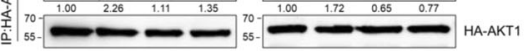

U.2 os

H1299

\section{B}

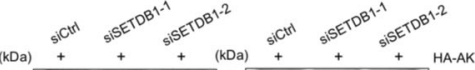

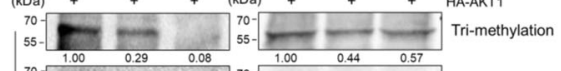

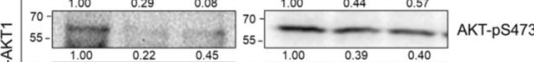

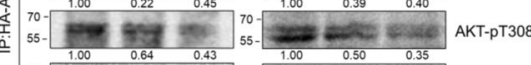

${ }_{55}^{70}=-0.64-0.43$

$\mathrm{U}-2 \mathrm{OS}$

H1299

D

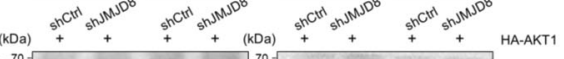

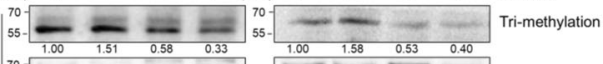

HA-AKT1

U-2 OS H1299

E

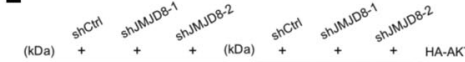

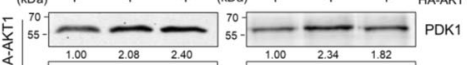

HA-AKT1

${ }_{55}^{70} \rightleftharpoons \frac{70}{2}=20$ POK1

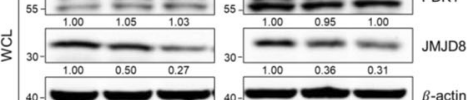

${ }_{\mathrm{H}-2 \text { OS }}{ }_{\mathrm{H} 1299}$

G

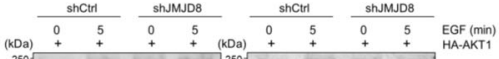

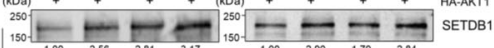

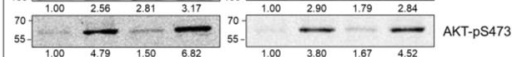

AKT-PT308

${ }_{55}^{70} \square-\cdots-{ }_{55}^{70}=-\infty$ Рок1

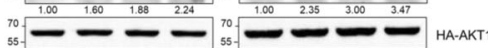

${ }_{150-}^{250}-\ldots-m-$ SETDB $1_{150-}^{250}$

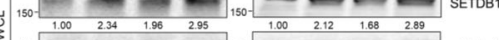

-

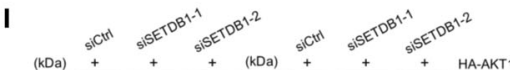

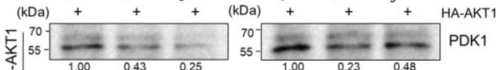

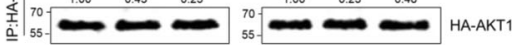

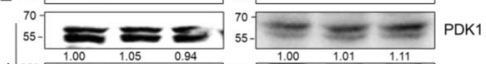

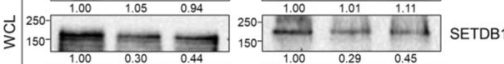
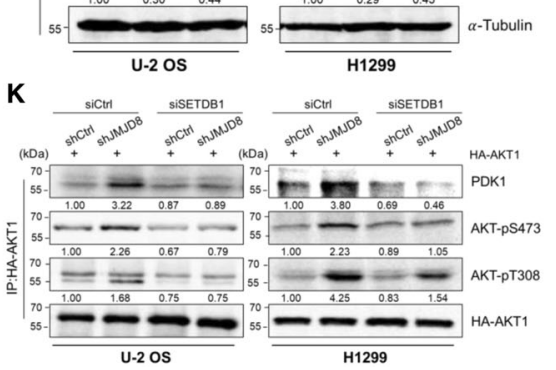

Fig. 6 
A

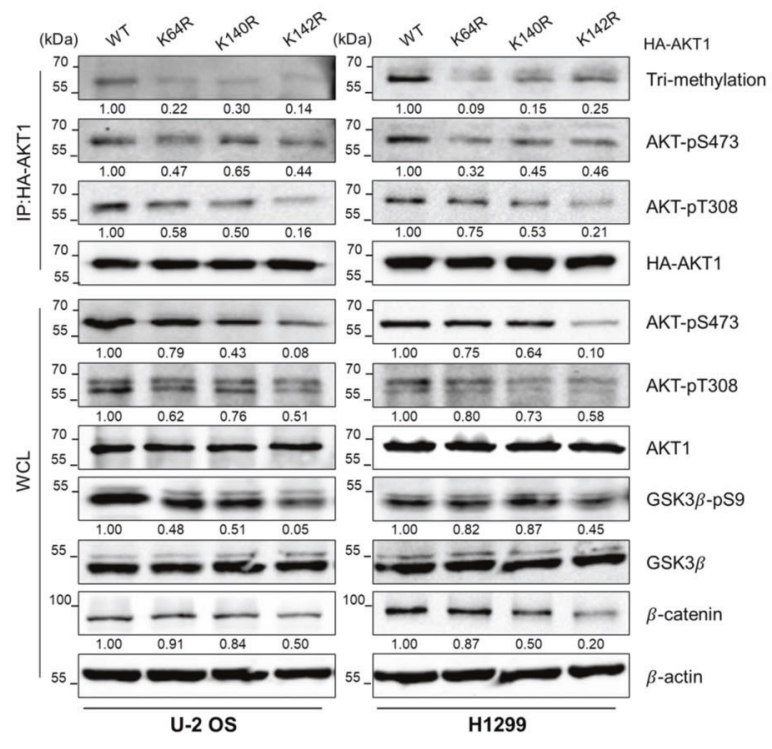

C

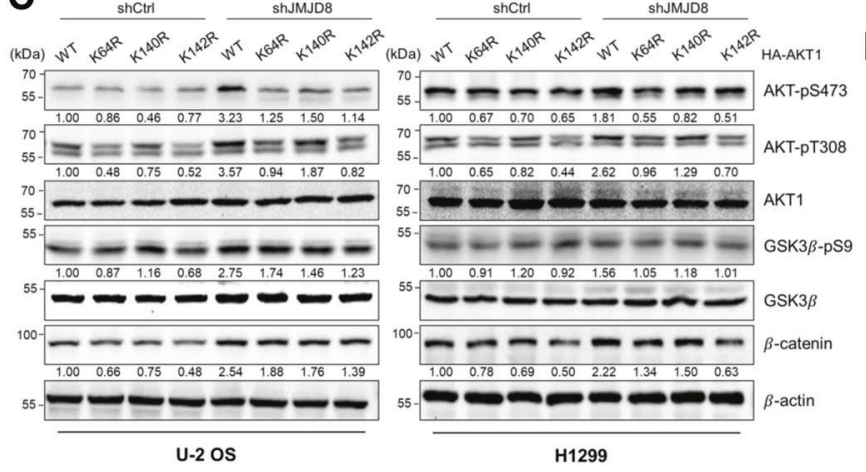

B

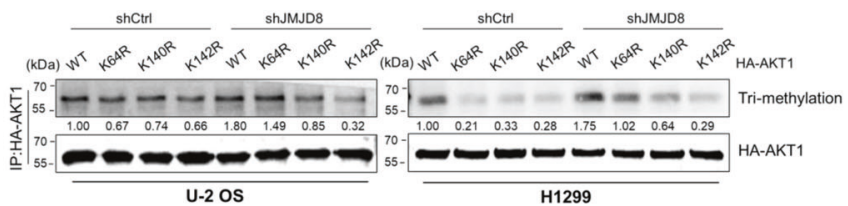

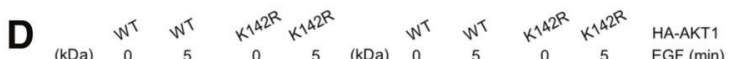

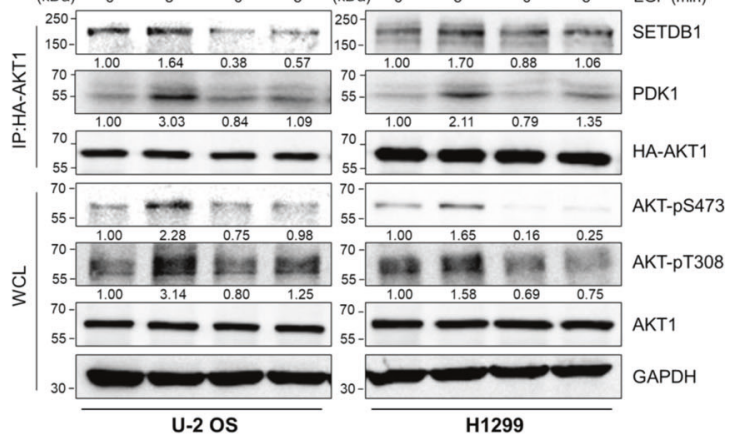

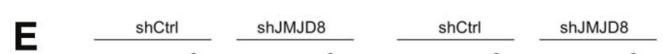
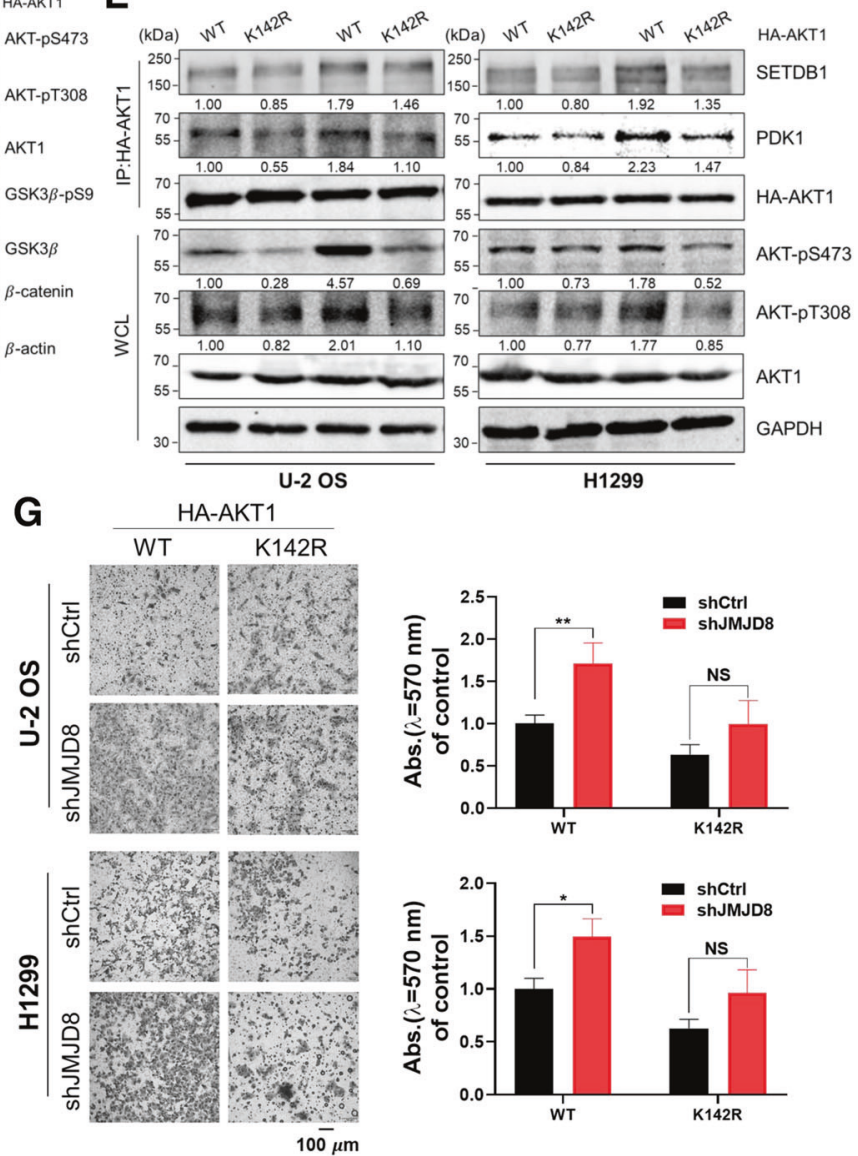

Fig. 7

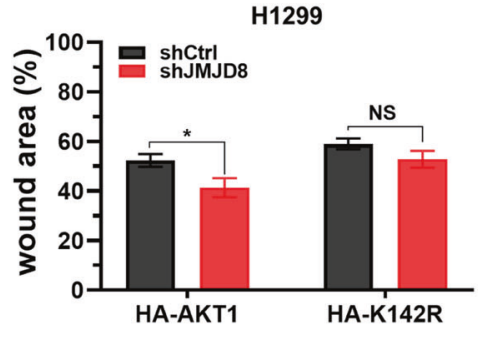


A

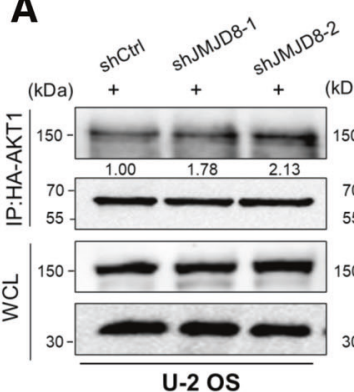

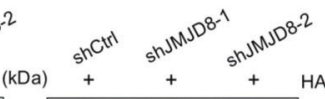

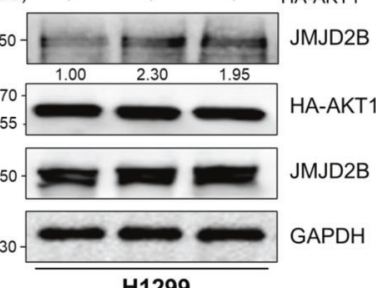

C

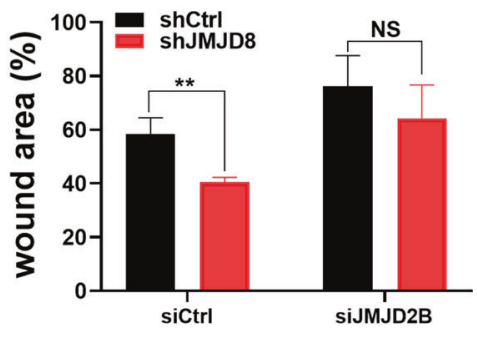

H1299

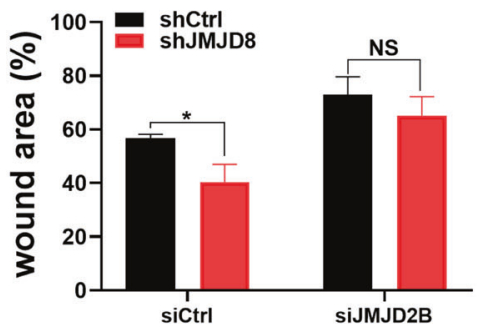

E

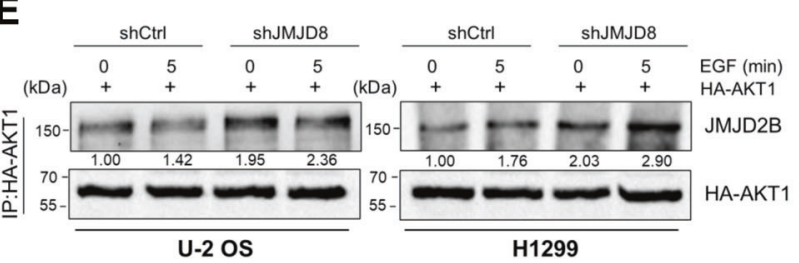

G

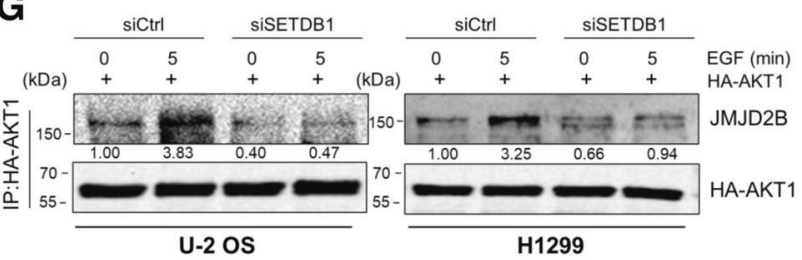

I

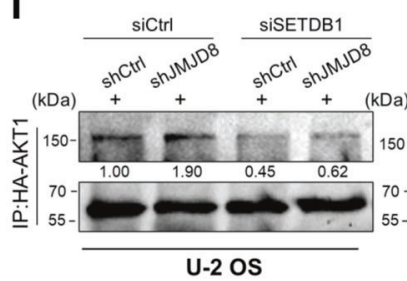

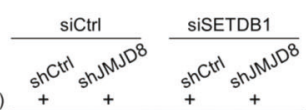

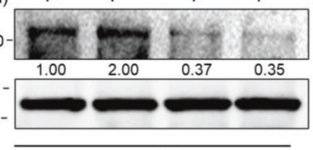

H1299

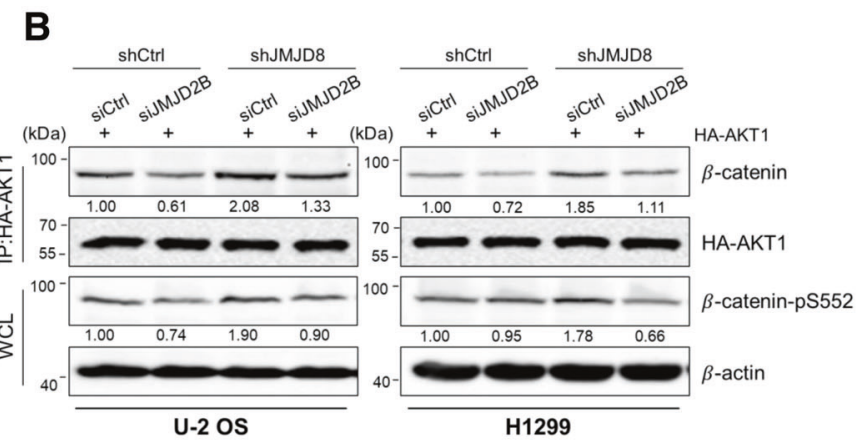

D
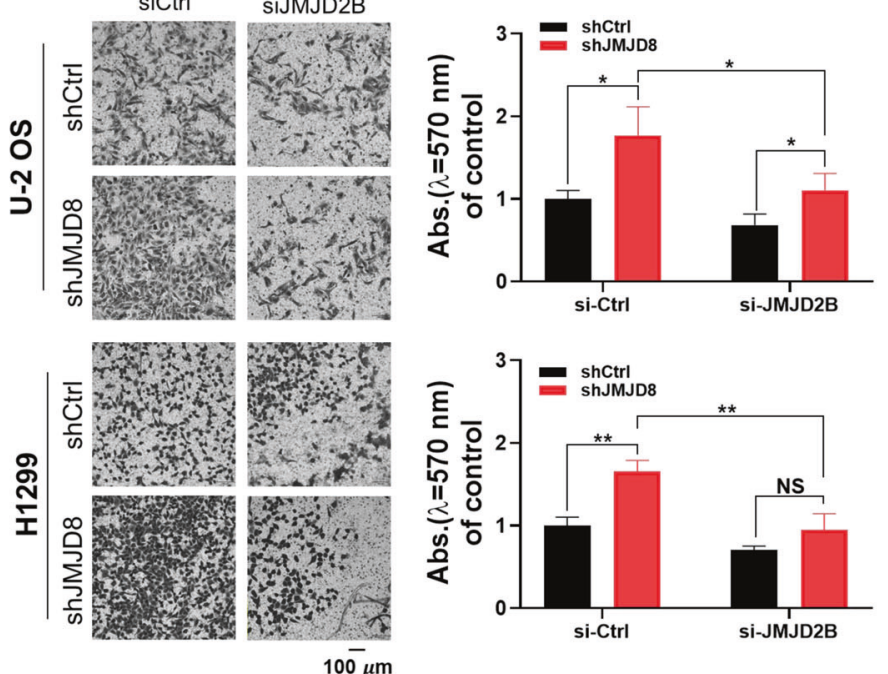

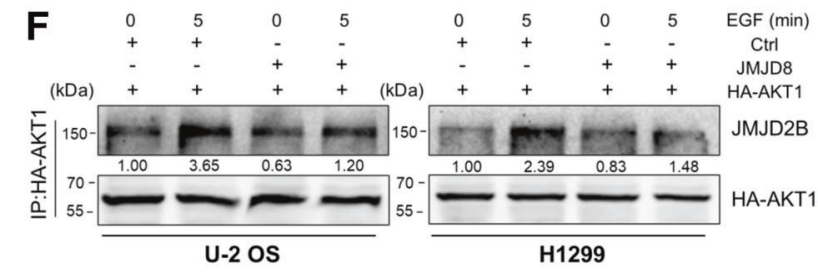

H

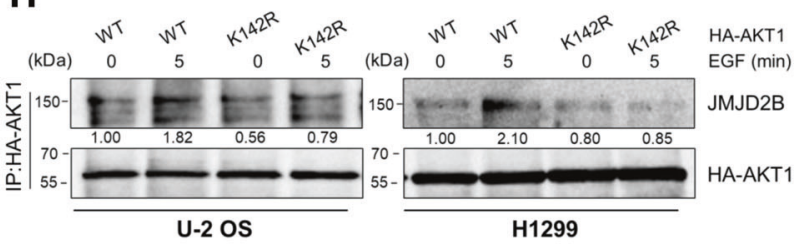

J shCtrl $\frac{\text { shJMJD8 }}{\text { shCtrl }}$ shJMJD8

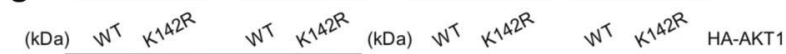
U-2 OS

Fig. 8 